\title{
Chronic thromboembolic pulmonary hypertension related to hemangiolymphangioma
}

\author{
Tsuneyuki Nakamura*, Keita Tamanuki, Giyo Ko, Masato Oguri, Chisato Akita, Chika Kitaoka, \\ Toshimi Nakamura, Yutaka Saikawa
}

Department of Pediatrics, Kanazawa Medical University, Ishikawa, Japan; *Corresponding Author: p-tune@kanazawa-med.ac.jp

Received 15 November 2013; revised 23 December 2013; accepted 10 January 2014

Copyright (C) 2014 Tsuneyuki Nakamura et al. This is an open access article distributed under the Creative Commons Attribution License, which permits unrestricted use, distribution, and reproduction in any medium, provided the original work is properly cited. In accordance of the Creative Commons Attribution License all Copyrights (C) 2014 are reserved for SCIRP and the owner of the intellectual property Tsuneyuki Nakamura et al. All Copyright (C) 2014 are guarded by law and by SCIRP as a guardian.

\section{ABSTRACT}

Hemangiolymphangioma $(\mathrm{HL})$ is a congenital anomaly and histologically benign tumor, which was composed of both the lymphatic and the blood vessels. We report an adult case of $\mathrm{HL}$ complicated by chronic thromboembolic pulmonary hypertension (CTEPH) in a 20-year-old female. Gastrointestinal bleeding scintigraphy and operative findings elucidate a close relationship between CTEPH and residual HL. This case indicates that $\mathrm{HL}$ survivors with remaining left-to-right shunt might lead to CTEPH during the long-term follow-up.

\section{KEYWORDS}

\section{Hemangiolymphangioma; Chronic Thromboembolic Pulmonary Hypertension; Long-Term Follow-Up}

\section{INTRODUCTION}

This report describes an adult case of hemangiolymphangioma (HL) complicated by chronic thromboembolic pulmonary hypertension (CTEPH) in a 20-year-old female patient. HL is a congenital anomaly caused by anomalous embryological development of the lymphatic and vascular system [1]. Therefore, most reports of HL have involved perinatal diagnosis [2], childhood diagnosis [3], or neonatal management [4]. Furthermore, CTEPH has not been described in HL survivors. The present report emphasizes the long-term follow-up of coagulation in HL survivors.

\section{CASE REPORT}

A 20-old-female was referred to our outpatient de- partment with recent chest pain and severe dyspnea. She was diagnosed postnatally with systemic and multiple HLA with high-output heart failure, which pediatric surgeons operated on to remove the tumor three times in early childhood. However, the patient had residual HLA in the abdomen, thorax, and systemic skin.

After hospitalization, right heart failure was diagnosed echocardiographically as corpulmonale, supported by elevated levels of brain natriuretic peptide $(577 \mathrm{pg} / \mathrm{ml})$ and possible pulmonary thrombosis on magnetic resonance images. Initially, we did not understand the relationship between these symptoms and residual HL. We performed gastrointestinal bleeding scintigraphy $(99 \mathrm{~m}$ Tc-diethylenetriaminepentaacetic acid-human serum albumin, 99 mTc-HSA-D) because she had unexpectedly low hemoglobin $(4.5 \mathrm{~g} / \mathrm{dl})$ at hospitalization. The patient's medical history, family history, and laboratory examinations did not reveal definitive evidence of an inherited coagulation disorder; however, we strongly suspected that she had HLA-related thrombosis due to abnormal pooling in accordance with a residual HL site (Figure 1). Therefore, we tried to start anticoagulation therapy, which improved the severe symptoms and clinical laboratory data. After improvement of her clinical symptoms, the patient was diagnosed with CTEPH because of the presence of residual pulmonary arterial hypertension based on catheterization and ventilationperfusion mismatch using scintigraphy [5]. The patient was discharged from our hospital after 1 month. Some of the previous symptoms recurred due to self-discontinuation of the antithrombotic medication.

Recently, she has started taking the antithrombotic medication again and presented at our outpatient department without symptoms. The patient had a baby at 27 years old, delivered by cesarean section. During the cesarean section, residual HLA in the abdominal cavity ap- 
peared to have a black clotting pool, similar to a bunch of grapes (Figure 2).

\section{DISCUSSION}

HL is a congenital anomaly and histologically benign tumor composed of both lymphatic and blood vessels [1] that has the potential to occur at any anatomical location, including axillary [6], the urinary bladder [3], and parotid gland [7]. Despite its benign histology, the huge cystic mass may compress, invade, and destroy normal tissue. A large left-to-right shunt flow may lead to highoutput heart failure [8]. Therefore, HL survivors might have a characteristically small size, small shunt, or successful operative extraction.

However, no reports are available on the long-term outcomes of HL survivors because of the benign character of HL. Furthermore, thrombosis has not been reported in HL. In the present case, hemorrhage scintigraphy provided a possible diagnosis of pulmonary thrombosis. The patient was definitively diagnosed with pulmonary thrombosis based on the recurrence of symptoms without
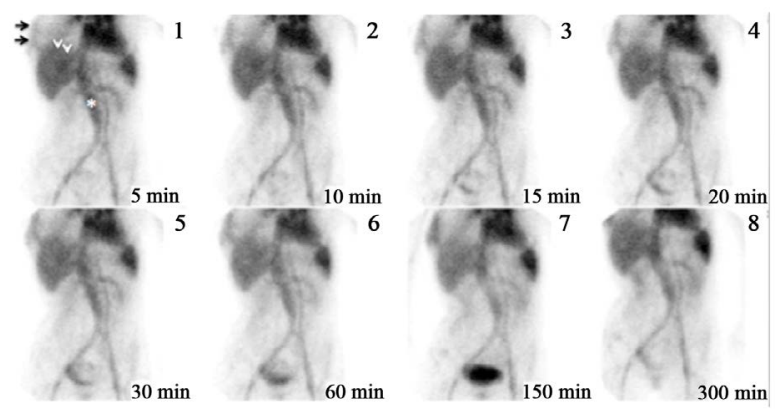

Figure 1. Gastrointestinal bleeding scintigraphy shows an enlarged inferior vena cava (asterisk) and abnormal pooling in the abdominal cavity (arrow) and thoracic cavity (arrowheads).

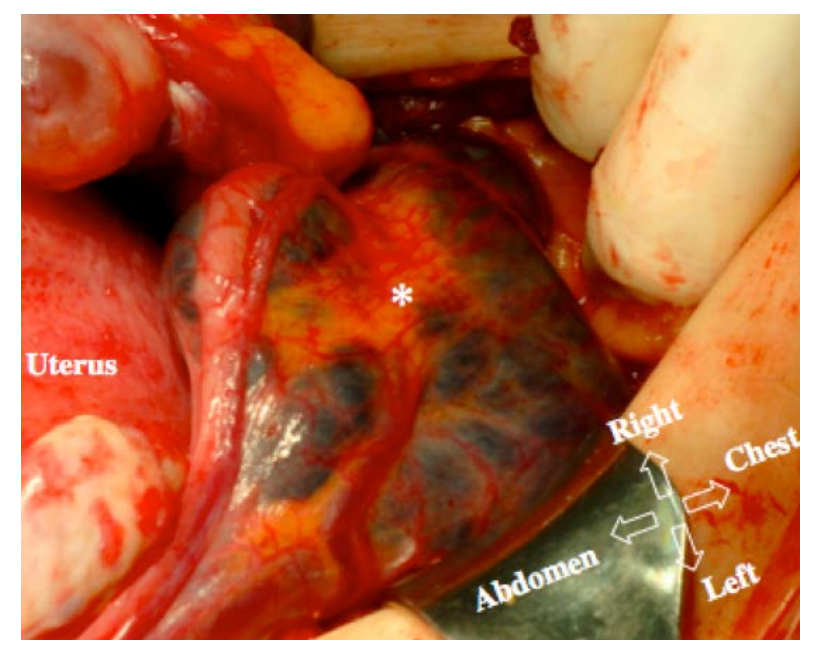

Figure 2. Residual hemangiolymphangioma in the abdominal cavity, with a black clotting pool similar to a bunch of grapes, in front of the liver (asterisk). anticoagulation.

When considering the cause of CTEPH, it is important that HL does not have only two histological components, but also two functions. The lymphatic aspect of HL is cystic mass formation in which the cyst is filled with lymph fluid but does not affect systemic circulation. On the other hand, the blood vessel aspect has the communication with normal vessels, which may cause highoutput heart failure due to a left-to-right shunt [8]. The latter is an important function in the long-term follow-up of HL survivors. Operative findings elucidate a close relationship between CTEPH and residual HL.

Clinical symptoms may be relieved in HL survivors who undergo surgery, but survivors with left-to-right shunt might experience CTEPH during long-term followup. 99 mTc-HSA-D scintigraphy is useful for examining the left-to-right shunt in residual HL.

\section{REFERENCES}

[1] Shetty, D.C., Urs, A.B., Rai, H.C., Ahuja, N. and Manchanda, A. (2010) Case series on vascular malformation and their review with regard to terminology and categorization. Contemporary Clinical Dentistry, 1, 259-262.

[2] Senoh, D., Hanaoka, U., Tanaka, Y., Tanaka, H., Hayashi, K., Yanagihara, T. and Hata, T. (2001) Antenatal ultrasonographic features of fetal giant hemangiolymphangioma. Ultrasound in Obstetrics \& Gynecology, 17, 252-254. http://dx.doi.org/10.1046/j.1469-0705.2001.00347.x

[3] Chandna, S., Bhatnagar, V., Mitra, D.K. and Upadhyaya, P. (1987) Hemangiolymphangioma of the urinary bladder in a child. Journal of Pediatric Surgery, 22, 1051-1052. http://dx.doi.org/10.1016/S0022-3468(87)80519-5

[4] Campos, M., Ortiz, V., Correa, M.S., Santiago B.P.J., Garcia, I., Garcia, L. and Valcárcel, M. (2008) Evidenced based management of neonatal hemangiolymphangioma: A case report. Boletín de la Asociación Médica de Puerto Rico, 100, 57-59.

[5] McNeil, K. and Dunning, J. (2007) Chronic thromboembolic pulmonary hypertension (CTEPH). Heart, 93, 11521158. http://dx.doi.org/10.1136/hrt.2004.053603

[6] Ozkur, A., Kervancioglu, S., Kervancioglu, R., Dikensoy, E., Inaloz, H.S. and Sirikci, A. (2007) Prenatal sonographic diagnosis of an extensive fetal axillary hemangiolymphangioma. Journal of Clinical Ultrasound, 35, 274-276. http://dx.doi.org/10.1002/jcu.20316

[7] Zacharia, T.T., Ittoop, A., Perumpillichira, J.J. and Chavhan, G. (2003) Sonographic appearance of a congenital parotid gland hemangiolymphangioma simulating malignancy in an infant. Journal of Clinical Ultrasound, 31, 493-496. http://dx.doi.org/10.1002/jcu.10205

[8] Rotas, M., Haberman, S., Merhi, Z.O. and Morcos, M. (2006) Prenatal diagnosis of giant fetal truncalhemangioma by means of 2- and 3-dimensional sonography with magnetic resonance imaging. Journal of Ultrasound in Medicine, 25, 527-531. 